\title{
Workplace ergonomics training intervention and its effect on quality of nursing work life among nurse interns
}

\author{
Hanaa Mohamed Abd Rabou ${ }^{1}$, Dalal Talaat Akel*2 \\ ${ }^{1}$ Nursing Administration, Faculty of Nursing, Ain Shams University, Egypt \\ ${ }^{2}$ Nursing Administration, Faculty of Nursing, British University, Egypt
}

Received: July 1, 2020

DOI: $10.5430 /$ cns.v8n3p35
Accepted: August 26, 2020

Online Published: September 7, 2020

\begin{abstract}
Objective: The current study aim is to evaluate impact of workplace ergonomics training intervention on the Intern nurses' work life quality.

Methods: The study accompanied through a quasi-experimental design with all nurse interns who registered in internship year, in operating rooms and critical care units at El Demerdash Hospital which are allied to Ain Shams University Hospitals. A triple-section questionnaire was used for data collection: First, part I - nurse interns' socio demographic profile. Part II self-administered knowledge questionnaire. Second, nurse interns' performance observational checklist. Third, Brooks' Quality of Nursing Work Life survey.

Results: The study reported that nurse intern' knowledge and practice related to workplace ergonomics were improved in the post intervention and follow up phases. Also, interns' total quality of nursing work life was highly statistically significant different during post intervention and follow up phases when compared with pre intervention phase.

Conclusions: The findings of this study concluded that ergonomics training intervention had positive impact on nurse interns' work life quality in post and after three months from the intervention of training intervention compared to the pre intervention phase. The study recommends that nurse interns should adhere to safety guidelines in all their practices and provides nurse interns with safe patient handling and mobility training programs.
\end{abstract}

Key Words: Nurse interns, Quality of nursing work life, Workplace ergonomics

\section{INTRODUCTION}

Nurse interns are responsible for assisting in the delivery of both direct and indirect patient care under the direction and supervision of a registered nurse. Occupational susceptibility of nurses may threaten the effectiveness of system of health in unindustrialized countries, particularly among nurses and nurse interns. ${ }^{[1]}$ The most of absenteeism days/sick leave of nurse interns at their clinical practice areas mostly result from their contact to occupational risks such as ergonomics and bodily hazards. ${ }^{[2]}$

Universally the word ergonomics is widely used these days in healthcare organizations. Ergonomics has just been characterized as a practical science concerned with manipulating and organizing belongings people use so that people and things interrelate most professionally and safely. ${ }^{[3]}$ The International Ergonomics Association defined Ergonomics as Egypt.

*Correspondence: Dalal Talaat Akel; Email: dalal.akel@bue.edu.eg; Address: Nursing Administration, Faculty of Nursing, British University, 
scientific based discipline concerned with the essential understanding of relations among people and other fundamentals of a system, and the job that spread over theory, values, data and approaches to develop the work duty to enhance peoples' well-being and overall system practice. ${ }^{[4]}$

Ergonomics in the workplace sheds light on nursing shortage, staff burnout and increasing quality of nursing care. Professions nowadays contribute to the need for safer conditions, better physical designs, and a stress on training and technology improvements. Positive steps have been taken in many aspects related to job injuries, poor training and poor techniques, which have negative effect on the workplace in all kinds of organizations, whether large or small. ${ }^{[5]}$ Nursing has its hazards, especially in hospitals, and clinics. Nurses are liable to back injury when moving patients, or using electrical equipment. ${ }^{[6]}$ Therefore, to enhance health care workers' quality of life at the hospital environment, an ergonomic training should be established in harmony with the physical, social and psychological characteristics. ${ }^{[3,7]}$

Work life quality is an effort to comprehend the connections among the core planes of the working setting so that cause and impact can be notable, and interventions properly battered. ${ }^{[8]}$ An increased work life quality is a vital matter for hospital services to have qualified, enthusiastic, and encouraged employees. Among diverse areas in health care locations, nurses have a main share among health care workers. Therefore, they should have an improved QWL to provide high-quality complete care to those who need assistance. They are the most appreciated resource of the society, who should be treated with admiration and respect as they are accountable for making a valuable influence. ${ }^{[9]}$

Work life quality includes four categories as the following: (a) "work life or home", which means the line between home life of nurses and their work; (b) "pattern", which means the arrangement of nurses' effort and defines the actual tasks nurses implement at their work setting. It includes work pressure, employment, and independence; (c) "work context", which includes the practice settings in which nurses' work and explores the impact of the work environment on both nurse and patient systems. It includes relationships with supervisory personnel, co-workers, inter-disciplinary health team colleagues, the provision of resources to do the job, and promotion of lifelong learning by the institution. Lastly, (d) work world, which means the impact of comprehensive societal effects and alteration of the performance of nursing, like respecting the profession. ${ }^{[10]}$

\subsection{Significance of the study}

The difficulty of giving patient care in the health care organization needs reconsidering this issue to security. Intern nurse's exposed to a wide range of risks in hospitals such as back pain and musculoskeletal complaints. ${ }^{[1]}$ Musculoskeletal complaints are considered a community health problem. In Egypt, it is considered an important professional issue among healthcare workers. Work problems have been allied with corporeal and sensitive effect on nurses and nurses' families; thus, it is definitely related to job displeasure and decrease in work life quality among nursing staff. ${ }^{[11]}$ Also, it is the common cause for the absenteeism of nursing staff in their specialized situation, which harshly impact their work life's quality and professional practice. ${ }^{[12]}$ Over 59 million healthcare providers experienced diversity of work-related risks, including organic, bodily, ergonomic, ecological, and emotional. Nursing profession is watched among 40 professions with increased occurrence of illnesses due to extreme work pressure. It is clear that physical and emotional health difficulties of nurses with more work stressors are vital issues in restricting the number and their work life quality. ${ }^{[13]}$

\subsection{Aim of the study}

The current study aim was to evaluate the effect of workplace ergonomics training intervention on intern nurses' quality of nursing work life through:

(1) Identifying nurse interns' knowledge level regarding workplace ergonomics before and after the training intervention.

(2) Measuring level of nurse interns' practice regarding workplace ergonomics before and after the training intervention.

(3) Comparing nurse interns' quality of work life before and after the training intervention.

\subsection{Hypotheses of the study}

To achieve the present study aim, two hypotheses were tested.

Hypothesis I: Nurse interns' knowledge and practice level regarding workplace ergonomics will be improved after implementing the training intervention.

Hypothesis II: Nurse interns' quality of nursing work life will be improved after implementing the training intervention.

\section{SUBJECTS AND METHODS}

\subsection{Research design}

A quasi-experimental research design was utilized in the current study.

\subsection{Study settings}

This study was conducted at Ain Shams University Hospitals, in operating rooms and critical care units, where the Nurse Interns have their training. It included four main hos- 
pitals namely, El-Demerdash Hospital, Ain Shams University Hospital, Pediatrics Hospital and Academic Heart Institute.

\subsection{Subjects}

The subject of this study consisted of all available nurse interns having their training in the aforementioned settings during the data collection period (academic year 2018-2019). The study sample was ninety nurse interns, thirty four males and fifty six females.

\subsection{Tools of data collection}

Three data collection tools were utilized for collecting data namely.

\subsubsection{Self-administered knowledge questionnaire}

It aimed to assess nurse interns' knowledge about workplace ergonomics (pre/posttest). This questionnaire sheet was designed by the investigator based on some previous literatures. ${ }^{[14-16]}$ It included two parts as follows:

Part (1): Socio-demographic sheet: to gather socio demographic data such as age, gender, marital status, and attendance of training programs.

Part (2): It consisted of twenty five MCQ categorized into eight sub-groups to assess Nurse Interns' knowledge toward the following: (meaning $\&$ benefits of workplace ergonomics (three questions); principles of workplace ergonomics (four questions); workplace ergonomics' hazards (two questions); job tasks that will result in injury (two questions); safe patient handling techniques (five questions); lifting and carrying supplies and equipment(three questions); prolonged standing (two questions); practices to avoid back injuries (four questions).

Scoring system: Nurse Interns' knowledge sheet included twenty five questions; responses for the questions were in the form of MCQ. The correct responses were given (one score), the incorrect responses were given (zero). Nurse Interns' knowledge level was considered high if the percent score is more than $75 \%$, while it is considered moderate if the percent score ranged between $60 \%$ to $75 \%$ and low if the percent score is less than $60 \%$.

\subsubsection{Nurse interns' performance observational checklist}

It is used to assess nurse interns' workplace ergonomics practices pre and post training intervention. It was designed by the investigator after reviewing some literatures. ${ }^{[14-16]}$ It included 30 practice steps which were categorized into six main parts as the following:

- Part one was utilized to assess nurse interns' performance regarding positioning and repositioning the patients. It consisted of (four steps).
- Part two was utilized to assess nurse interns' performance regarding lifting and holding legs, arms, and head. It consisted of (four steps).

- Part three was utilized to assess nurse interns' practices regarding prolonged standing. It consisted of (six steps).

- Part four was utilized to assess nurse interns' performance regarding retraction. It consisted of (six steps).

- Part five was utilized to evaluate nurse interns' performance regarding lifting and moving objects. It consisted of (six steps).

- Part six was utilized to assess nurse interns' practices about pushing; pulling and moving objects on wheels it consisted of (four steps).

Scoring system: Answers for the thirty practice questions were either done correct or incorrect. One score was assigned to correct practice and zero for incorrect practice. The total answers for the observation checklist were (thirty scores). The level of performance of nurse interns was considered satisfactory if $75 \%$ or more, while it was considered unsatisfactory if the percent score was less than $75 \%$.

\subsubsection{Brooks' Quality of Nursing Work Life survey}

It was designed by Brooks ${ }^{[17]}$ to assess nurse interns' quality of work life. It included (42-items) grouped under four dimensions, namely:

(1) Work life/home life dimension (seven items)

(2) Work design dimension (ten items)

(3) Work context dimension (twenty items)

(4) Work world dimension (five items)

Scoring system: Answers for each item were documented in the form of five-point Likert type scale: "strongly agree", "agree", "uncertain", "disagree", and "strongly disagree". The responses "strongly agree", "agree", "uncertain", "disagree", and "strongly disagree" in each section were scored five to one respectively. The scores of each dimension were summed up and then converted into a percent score. A score of $60 \%$ or higher (corresponding to agree/strongly agree) were considered as high quality of work life.

\subsubsection{Validity of the study tools}

An opinionnaire sheet was developed by the researchers to assess face and content validity of the suggested tools through experts' opinions, which were assessed through a group of experts. Face validity aimed at inspecting the items to determine whether the tools measure what is supposed to measure. Content validity was conducted to determine whether the tools cover the appropriate and necessary content as well as its relevance to the tools and the study aim. The jury group 
consisted of seven members; they were professors and assistant professors from departments of Nursing Administration, Medical Surgical Nursing and Community Health Nursing at Faculty of Nursing-Ain Shams University. The experts' opinions were asked to respond to each statement of the tools as "agree or disagree" or "agree with modification". Also, the authors examine the content validity of the instruments. Content validity ratio, content validity index and modified kappa statistic was performed.

\subsubsection{Reliability of the tools}

Internal consistency was done by Cronbach's Coefficient Alpha was (0.90) for the knowledge questionnaire and (0.94) for the nurse interns' performance observational checklist and (0.92) for Brooks' Quality of Work Life survey.

\subsection{Operational design}

The operational design for the current study included preparatory phase, pilot study, ethical considerations, and fieldwork.

\subsubsection{Preparatory phase}

It included reviewing past, current, national and international related literature and theoretical knowledge of several aspects of workplace ergonomics and quality of work life from the perspective of nurse interns using books, articles, internet, and periodicals. The researchers made some necessary adjustments on the instruments and process of the study based on results of the pilot study, although the analysis of pilot study data had added a lot of information to the researchers and helped them in sample size calculation.

\subsubsection{Pilot study}

Pilot study was implemented after an authorized approval was gained from the dean of Faculty of Nursing, Ain Shams University to the director the study settings. The pilot study included eighteen intern nurses; it was conducted to assess the simplicity, legibility, understandability, and feasibility of the tool. It was also used to find the probable problems that might face the investigators and restrict data collection to guesstimate the time needed to fill in the sheets. Based on the result of the pilot study, no modified actions were done.

\subsubsection{Ethical considerations}

- Verbal consent was taken from the participants after informing them about the aim and tools of the study.

- The participant's name was optional.

- The confidentiality of all the collected information was guaranteed, and the subjects were informed about their right to withdraw at any time.

- The participants were also assured about anonymity, and that all data will be used for the purpose of the study.
- The collected data were used for the research purposes only and stored in password protected computer.

\subsubsection{Field work}

It included four phases: planning phase, implementation phase, evaluation phase and follow up phase.

Planning phase: In this phase, the investigator reviews the recent related literatures for developing the data collection tools and for preparing the media needed for ergonomics' training intervention. The aim of the study was explained to nurse interns before collecting the data, as well as their permission to participate in the study was gained. Data collection tools were disseminated to nurse interns in the clinical areas by the investigator to evaluate knowledge of nurses regarding ergonomics to identify the learning requirements of nurses. Fifteen to twenty minutes were taken to fill this sheet. Also, observation checklist was distributed to nurse interns three times by the investigator before the intervention. Thirty minutes were taken to fill in this sheet. The investigator develops the ergonomics training program which was revised for content validity by a group of seven experts and the needed modifications were done according to the experts' opinions.

Implementation phase: The training program was directed for nurse interns at their training areas. Nurse interns were divided into two main groups. The first group was nurse interns whose training was at Ain Shams University Hospital and Academic Heart Institute, their total number was (forty five). The second group was nurse interns whose training was at El Demerdash and Pediatrics Hospital, their total number was (forty six). Each group was divided into two subgroups according to their work schedule. The first subgroup (twenty two) attended the program sessions on Sunday and Monday, while the second subgroup (twenty three) attended the program sessions on Tuesday and Wednesday. The program took about twelve days for each main group. The total program contents were clarified over eight sessions, four hours for each session; two hours for theory and two hours for practice. The training program sessions implemented four days/week (four hours/day).It was carried out from 12:00 a.m. to 2:00 p.m. except the first week for each subgroup; it was one day only. The first session included the pretest and the investigator clarified the program aim, outlines and methods of evaluations. Lecture and group discussions were utilized for giving the theoretical part, which was related to (concept, benefits and principles of workplace ergonomics, Workplace ergonomics' hazards, job tasks that will result in injury and challenges of ergonomics in the operating rooms and critical care areas) while demonstration and re-demonstration was utilized in the practical part. The practical part about 
ergonomic hazards and how-to prevent (musculoskeletal disorders and back injuries, working postures and movements, handling the heavy patients and objects, transport the surgical carts, and making retraction during surgery and standing for long periods of time).

Table 1. Distribution of study sample demographic characteristic $(n=90)$

\begin{tabular}{|c|c|c|}
\hline \multirow{2}{*}{ Items } & \multicolumn{2}{|c|}{ Nurse Interns $(\mathrm{n}=90)$} \\
\hline & Frequency & Percent \\
\hline \multicolumn{3}{|c|}{ Age (in years) } \\
\hline $22-23$ & 73 & 80.2 \\
\hline $24-25$ & 18 & 19.8 \\
\hline Mean $\pm S D$ & \multicolumn{2}{|c|}{$22.67 \pm 0.83$} \\
\hline Range & \multicolumn{2}{|c|}{$22-25$} \\
\hline \multicolumn{3}{|l|}{ Gender } \\
\hline Male & 34 & 37.4 \\
\hline Female & 56 & 62.6 \\
\hline \multicolumn{3}{|l|}{ Residence } \\
\hline Urban & 77 & 85.7 \\
\hline Rural & 13 & 14.3 \\
\hline \multicolumn{3}{|c|}{ Marital status } \\
\hline Single & 67 & 74.4 \\
\hline Married & 23 & 25.6 \\
\hline \multicolumn{3}{|c|}{ Training programs } \\
\hline Yes & 18 & 19.8 \\
\hline No & 72 & 80.2 \\
\hline
\end{tabular}

Evaluation phase: After application of the program, all tools were completed again immediately after the program. An evaluation of the impact of the training program was completed by finding out the alteration between nurse interns' knowledge and performance in the pre and post training intervention.

Follow-up phase: This phase was performed after three months of the implementation of training intervention using the same data collection sheets. The aim was to evaluate the retained knowledge and practice of nurse interns.

\subsection{Administrative design}

- Ethical approval was received from Faculty of Nursing, Ain-Shams University, and Scientific Research Ethical Committee.

- Consent to conduct the study was received from the Dean of Faculty of Nursing, Ain-Shams University.

\subsection{Statistical design}

Data entry was finalized using SPSS V17 computer software package. Data were offered using descriptive statistics in the form of frequencies and percentages for qualitative variables, and means \pm standard deviations for quantitative variables. Paired $t$-test was used to compare between two means in the same studied group pre and post intervention and between two means post intervention and during follow up phase. Pearson correlation co-efficient $(r)$ was utilized for evaluation of the inter-relationship among quantitative variables. In order to identify the independent predictor of quality of work life score, multiple linear regression analysis was used.

\section{Results}

Table 1 describes the socio-demographic characteristics of the nurse interns, approximately two thirds $(80.2 \%)$ of nurse interns were 22-23 years old, with a mean age $22.67 \pm 0.83$ years. Also, more than half of them $(62.6 \%)$ were female. The majority of nurse interns $(85.7 \%)$ were from urban areas. Also, two thirds $(74.4 \%)$ of them were single. With regard to attending training program, the majority of them $(80.2 \%)$ did not attend programs.

Table 2. Score of nurse interns' knowledge regarding workplace ergonomics through intervention phases $(\mathrm{n}=90)$

\begin{tabular}{|c|c|c|c|c|c|}
\hline \multirow[b]{2}{*}{ Items } & \multicolumn{3}{|c|}{ Mean $\pm S D$} & \multicolumn{2}{|c|}{ Paired Samples Test } \\
\hline & Pre & Post & Follow up & $\begin{array}{l}\text { Pre \& Post } \\
\left(t_{1}, p \text {-value }\right) \\
\end{array}$ & $\begin{array}{c}\text { Pre \& Follow up } \\
\left(t_{2}, p \text {-value }\right)\end{array}$ \\
\hline Concept \& benefits of workplace ergonomics & $3.43 \pm 0.67$ & $5.36 \pm 0.94$ & $5.17 \pm 1.03$ & $\begin{array}{c}15.68 \\
<.000^{* *}\end{array}$ & $\begin{array}{l}2.35 \\
<.05^{*}\end{array}$ \\
\hline Principles of workplace ergonomics & $4.40 \pm 0.63$ & $7.28 \pm 1.23$ & $7.42 \pm 0.96$ & $\begin{array}{l}19.43 \\
<.000^{* *}\end{array}$ & $\begin{array}{l}2.32 \\
<.05^{*}\end{array}$ \\
\hline Workplace ergonomics' hazards & $2.20 \pm 0.40$ & $3.50 \pm 0.77$ & $3.27 \pm 078$ & $\begin{aligned} & 14.23 \\
&<.000^{* *}\end{aligned}$ & $\begin{aligned} & 1.20 \\
< & .05^{*}\end{aligned}$ \\
\hline Job tasks that will result in injury & $2.27 \pm 0.47$ & $3.40 \pm 0.3$ & $3.62 \pm 0.68$ & $\begin{aligned} & 13.51 \\
&<.000^{* *}\end{aligned}$ & $\begin{aligned} & 2.18 \\
&<.05^{*}\end{aligned}$ \\
\hline Safe patient handling techniques & $5.30 \pm 0.64$ & $8.47 \pm 1.72$ & $8.69 \pm 1.46$ & $\begin{array}{l}16.57 \\
<.000^{* *}\end{array}$ & $\begin{aligned} & 2.46 \\
&<.01^{* *}\end{aligned}$ \\
\hline Lifting and carrying supplies and equipment & $3.30 \pm 0.57$ & $5.17 \pm 1.11$ & $4.99 \pm 1.25$ & $\begin{array}{l}13.62 \\
<.000^{* *}\end{array}$ & $\begin{aligned} & 2.68 \\
< & .00^{* *}\end{aligned}$ \\
\hline Prolonged standing & $2.24 \pm 0.43$ & $3.44 \pm 0.77$ & $3.64 \pm 0.66$ & $\begin{aligned} & 13.18 \\
&<.000^{* *}\end{aligned}$ & $\begin{aligned} & 3.48 \\
&<.001^{* *}\end{aligned}$ \\
\hline Tips to avoid back injuries & $4.36 \pm 0.66$ & $6.78 \pm 1.38$ & $7.01 \pm 1.15$ & $\begin{array}{l}15.26 \\
<.000^{* *}\end{array}$ & $\begin{aligned} & 2.61 \\
&<.01^{* *}\end{aligned}$ \\
\hline
\end{tabular}

Note. ${ }^{*}$ Statistically significant at $p<.05 ;{ }^{* *}$ High Significant at $p<.01$ 
Table 3. Score of nurse interns' practices regarding workplace ergonomics throughout intervention phases $(\mathrm{n}=90)$

\begin{tabular}{|c|c|c|c|c|c|}
\hline \multirow[b]{2}{*}{ Items } & \multicolumn{3}{|c|}{ Mean $\pm S D$} & \multicolumn{2}{|c|}{ Paired Samples Test } \\
\hline & Pre & Post & Follow up & $\begin{array}{l}\text { Pre \& Post } \\
\left(t_{1}, p \text {-value }\right)\end{array}$ & $\begin{array}{c}\text { Pre \& Follow up } \\
\left(t_{2}, p \text {-value }\right)\end{array}$ \\
\hline Practices regarding positioning and repositioning the patients & $3.87 \pm 0.99$ & $6.42 \pm 1.47$ & $6.23 \pm 1.23$ & $\begin{array}{c}13.81 \\
<.000^{* *}\end{array}$ & $\begin{array}{l}2.99 \\
<.00^{* *}\end{array}$ \\
\hline Lifting legs, arms, and head & $3.79 \pm 0.98$ & $6.78 \pm 1.27$ & $6.51 \pm 1.15$ & $\begin{array}{c}19.78 \\
<.000^{* *}\end{array}$ & $\begin{aligned} & 4.12 \\
< & .000^{* *}\end{aligned}$ \\
\hline Practices regarding prolonged standing & $6.03 \pm 1.49$ & $10.11 \pm 1.99$ & $10.43 \pm 2.03$ & $\begin{array}{c}17.84 \\
<.000^{* *}\end{array}$ & $\begin{aligned} & 3.46 \\
< & .000^{* *}\end{aligned}$ \\
\hline Practices regarding retraction & $6.31 \pm 1.45$ & $10.74 \pm 1.84$ & $10.42 \pm 1.83$ & $\begin{array}{c}20.74 \\
<.000^{* *}\end{array}$ & $\begin{aligned} & 4.37 \\
< & .000^{* * *}\end{aligned}$ \\
\hline Practices regarding lifting and moving objects & $6.22 \pm 1.42$ & $10.77 \pm 1.81$ & $10.48 \pm 1.82$ & $\begin{array}{c}19.34 \\
<.000^{* *}\end{array}$ & $\begin{array}{l}3.13 \\
<.00^{* * *}\end{array}$ \\
\hline Pushing, pulling and moving something on wheels & $3.79 \pm 0.97$ & $7.10 \pm 1.21$ & $7.32 \pm 1.98$ & $\begin{array}{c}20.39 \\
<.000^{* *}\end{array}$ & $\begin{array}{l}3.25 \\
<.00^{* * *}\end{array}$ \\
\hline
\end{tabular}

Note. ${ }^{*}$ Statistically significant at $p<.05 ;{ }^{* *}$ High Significant at $p<.01$

Table 2 shows that there is an improvement in knowledge of nurse interns regarding workplace ergonomics during post intervention and follow up phases when compared with pre intervention phase $(p<.001)$.
Table 3 shows that there is an improvement in nurse interns' practice regarding workplace ergonomics during post intervention and follow up phases, when compared with pre intervention phase $(p<.01)$.

Table 4. Nurse Interns' quality of work life throughout intervention phases

\begin{tabular}{|c|c|c|c|c|c|}
\hline \multirow[b]{2}{*}{ Items } & \multicolumn{3}{|c|}{ Mean $\pm S D$} & \multicolumn{2}{|c|}{ Paired Samples Test } \\
\hline & Pre & Post & Follow up & $\begin{array}{l}\text { Pre \& Post } \\
\left(t_{1}, p \text {-value }\right)\end{array}$ & $\begin{array}{c}\text { Pre \& Follow up } \\
\quad\left(t_{2}, p \text {-value }\right)\end{array}$ \\
\hline Work life/home life dimension & $19.07 \pm 5.51$ & $28.66 \pm 5.58$ & $28 . .3 \pm 5.62$ & $\begin{array}{c}16.88 \\
<.000^{* *}\end{array}$ & $\begin{array}{c}3.10 \\
<.00^{* *}\end{array}$ \\
\hline Work design dimension & $27.06 \pm 4.88$ & $41.39 \pm 7.31$ & $40.86 \pm 7.50$ & $\begin{array}{l}18.52 \\
<.000^{* *}\end{array}$ & $\begin{array}{l}2.18 \\
<.05^{*}\end{array}$ \\
\hline Work context dimension & $51.58 \pm 10.83$ & $86.09 \pm 13.43$ & $85.66 \pm 13.45$ & $\begin{array}{l}22.74 \\
<.000^{* *}\end{array}$ & $\begin{array}{c}2.41 \\
<.01^{* *}\end{array}$ \\
\hline Work world dimension & $14.81 \pm 4.15$ & $22.68 \pm 3.10$ & $22.07 \pm 3.00$ & $\begin{array}{c}14.49 \\
<.000^{* * *}\end{array}$ & $\begin{array}{l}2.24 \\
<.05^{*}\end{array}$ \\
\hline Total quality of work life & $112.5 \pm 18.58$ & $178.8 \pm 23.77$ & $177.6 \pm 24.67$ & $\begin{array}{l}27.15 \\
<.000^{* * *}\end{array}$ & $\begin{array}{l}1.92 \\
<.05^{*}\end{array}$ \\
\hline
\end{tabular}

Note. ${ }^{*}$ Statistically significant at $p<.05 ;{ }^{* *}$ High Significant at $p<.01$

Table 4 indicates that nurse interns' total quality of nursing tervention and follow up phases when compared with pre work life as well as work life/home life and work context intervention phase $(p<.01)$ respectively. were highly statistically significant different during post in-

Table 5. Correlations between total knowledge regarding workplace ergonomics, total ergonomics' practice score and total quality of work life score throughout intervention phases

\begin{tabular}{|c|c|c|c|c|c|c|}
\hline \multirow{3}{*}{ Parameter } & \multicolumn{6}{|c|}{ Total ergonomics practice score } \\
\hline & \multicolumn{2}{|c|}{ Pre } & \multicolumn{2}{|c|}{ Post } & \multicolumn{2}{|c|}{ Follow up } \\
\hline & $r$ & $p$-value & $r$ & $p$-value & $r$ & $p$-value \\
\hline Total knowledge regarding Workplace Ergonomics & 0.231 & $<.05^{*}$ & 0.354 & $<.05^{*}$ & 0.339 & $<.05^{*}$ \\
\hline Total Quality of Work Life & 0.460 & $<.000^{* *}$ & 0.540 & $<.000^{* * *}$ & 0.630 & $<.000^{* *}$ \\
\hline
\end{tabular}

Note. ${ }^{*}$ Statistically significant at $p<.05 ;{ }^{* *}$ High Significant at $p<.01$ 
Table 5 indicates that there was a strong correlation between gonomics' practice score and total quality of nursing work total knowledge regarding workplace ergonomics, total er- life score throughout intervention phases.

Table 6. Best fitting multiple liner regression model for the score of total quality of work life score immediate post training program

\begin{tabular}{|c|c|c|c|c|c|}
\hline \multirow{2}{*}{ Model } & \multicolumn{2}{|c|}{ Unstandardized Coefficients } & \multirow{2}{*}{$\begin{array}{c}\begin{array}{c}\text { Standardized } \\
\text { Coefficients }\end{array} \\
\text { Beta }\end{array}$} & \multirow{2}{*}{$t$} & \multirow{2}{*}{ Sig. } \\
\hline & $\mathbf{B}$ & Std. Error & & & \\
\hline (Constant) & 323.594 & 41.396 & & 7.817 & .000 \\
\hline Age & -.023 & 6.312 & .000 & -.004 & .997 \\
\hline Gender & -12.584 & 5.450 & -.260 & -2.309 & .023 \\
\hline Marital status & -12.606 & 6.332 & -.233 & -1.991 & .050 \\
\hline Training programs & 8.204 & 6.181 & .139 & 1.327 & .188 \\
\hline Total knowledge regarding Workplace Ergonomics score & 7.597 & 8.016 & .289 & .2 .968 & .013 \\
\hline Total Ergonomics practice score & 4.065 & 1.176 & .351 & 3.455 & .001 \\
\hline
\end{tabular}

Note. $R=0.43$; Model ANOVA: $F=3.115, p<.01^{* *}$; a. Predictors: Age Gender, Marital status, Training, total knowledge regarding Workplace Ergonomics score, Total Ergonomics practice score; $b$. Dependent Variable: Total Quality of Work Life score

Table 7. Best fitting multiple liner regression models for the score of total quality of work life score immediate follow up training program

\begin{tabular}{|c|c|c|c|c|c|}
\hline \multirow[t]{2}{*}{ Model } & \multicolumn{2}{|c|}{ Unstandardized Coefficients } & \multirow{2}{*}{$\begin{array}{c}\begin{array}{c}\text { Standardized } \\
\text { Coefficients }\end{array} \\
\text { Beta }\end{array}$} & \multirow[t]{2}{*}{$t$} & \multirow[t]{2}{*}{ Sig. } \\
\hline & B & Std. Error & & & \\
\hline (Constant) & 330.088 & 42.036 & & 7.853 & .000 \\
\hline Age & -.209 & 6.506 & -.003 & -.032 & .974 \\
\hline Gender & -14.14 & 5.640 & -.281 & -2.507 & .014 \\
\hline Marital status & -13.026 & 6.560 & -.23 & -1.986 & .050 \\
\hline Training programs & 7.073 & 6.414 & .115 & 1.103 & .273 \\
\hline Total knowledge regarding Workplace Ergonomics score & 6.173 & .3323 & .279 & 2.687 & .009 \\
\hline Total Ergonomics practice score & 4.367 & 1.203 & .363 & 3.631 & .000 \\
\hline
\end{tabular}

Note. $R=0.44$; Model ANOVA: $F=3.363, p<.01^{* *}$; a. Predictors: Age Gender, Marital status, Training, total knowledge regarding Workplace Ergonomics score, Total Ergonomics practice score; b. Dependent Variable: Total Quality of Work Life score

Table 6 displays that nurse interns' gender and marital status were negative dependent predicator for the score of total quality of nursing work life immediate post training intervention, while total quality of nursing work life knowledge score, and total ergonomics practice score were positive dependent predicator for the score of total quality of nursing work life immediate post training intervention. As indicated by the value of "R", they explain $43 \%$ of the variation of emotional intelligence score.

Table 7 displays that nurse interns' gender and marital status were negative dependent predicator for the score of total quality of nursing work life follow up training intervention, while total quality of nursing work life knowledge score, and total ergonomics practice score were positive dependent predicator for the score of total quality of nursing work life follow up training intervention. As indicated by the value of "R", they explain $44 \%$ of the variation of emotional intelligence score.

\section{DiscuSSION}

Musculoskeletal complaints are the foremost frequently experienced ergonomic workplace threat worldwide. ${ }^{[18]}$ The nursing profession entails many ergonomic hazards to nurses, with untoward consequences on the quality of nursing care as well as on nurses' wellbeing. Ergonomic interventions aimed at improving the workplace design proved to be economically efficient. ${ }^{[19]}$ However, nurses may resist the adoption of ergonomic changes in the work setting. ${ }^{[20]}$ Hence, ergonomics awareness is crucial in convincing them. ${ }^{[21]}$ This study aimed to evaluate the impact of workplace ergonomicstraining intervention on nurse interns' quality of nursing 
work life.

This is regarding the Nurse Interns' personal characteristics. In this study, it is noticeable that the highest percent of the total participating subject were twenty two to twenty three years old, while the minority of the total subject were twenty four to twenty five years old. In addition, the study showed that the female nurse interns were higher than male. From the researcher's point of view, it is normally found that the major of study subject were aged between were twenty two to twenty three years old because they are still in the internship year, which is immediately after graduation. In the same line, the high percentage of nurses is more among females than males. This is because in the past, according to our culture, the nursing profession depended on females only, but recently the male students started to join the Nursing college; this result was confirmed with $\mathrm{El}$ Ata et al. ${ }^{[2]}$

The study result also showed that the majority of the total study subject did not attend ergonomics-training program. This shows that Ergonomics training is a high-need to continue the efficiency of their work and avoid Musculoskeletal Disorders symptoms. Regarding the age and marital status, Afshar \& Hamedia ${ }^{[23]}$ mentioned that Musculoskeletal Disorders (MSDs) were also significantly higher among older nurses with more work experience; there was no significant relationship between gender, marital status, and education level.

Concerning Nurse Interns' knowledge regarding Workplace Ergonomics, the outcome of the current study confirmed that there was a highly statistical significant variation between nurse interns' information during, post and follow up phases when compared with pre intervention phase regarding prolonged standing and total knowledge. The prior results indicated that enhancement in nurse interns' knowledge can be qualified to the value of the applied training, since the baseline knowledge was giving them the simple knowledge regarding Workplace Ergonomics. According to the researchers' point of view, it is essential to become aware of the work experiences of nurse interns to change approaches, to enhance awareness of quality of work life and keep the nurse interns to the standard for quality patient care.

Congruent with this result, Choi \& Brings ${ }^{[24]}$ reported that there is an enhancement in comprehension of the values of Workplace Ergonomics and patient controlling approaches in the training program to handling fatty and overweight patients. In the same line, Stone $\&$ Deadrick $^{[25]}$ pointed that the health care organizations' focal point should be upgrading and application of progressive performs to lessen MSDs of the work, which in flip will satisfy nurses' requirements and will decorate the standard performance. This might be attributed to nurse interns' ignorance due to insufficient knowledge related to ergonomics through basic education in undergraduate studies or in their curriculum. Further, the prior result is in coherence with Tinubu et al., ${ }^{[26]}$ recognized that body mechanics training and awareness of their bodies has been shown to be actual in developing knowledge. Besides, Kochitty ${ }^{[27]}$ pointed that the majority of nurses had insufficient knowledge regarding suitable body mechanics in pre self-instructional module in proper utilization of body mechanics. In the same line, Garg \& Kapellusch ${ }^{[28]}$ mentioned that there is clear variation between the nurses scores pre and post intervention about lifting, handling, and moving objects.

Also, there is an improvement in nurse interns' practice as regard Workplace Ergonomics during post intervention and follow up phases when compared with pre intervention phase. In addition, the result showed significant improvement in total nurse interns' satisfactory level of practice regarding the Workplace Ergonomics. The previous finding agreed with Ali \& Abdel-Hakeim ${ }^{[14]}$ applying ergonomic program for nurses reinforced that there is a difference between the nurses' total practice pre and post intervention.

Regarding quality of nursing work life, this study revealed that nurse interns' total quality of nursing work life; like work life or home life and work setting were highly statistically significant different through post intervention and follow up phases when compared with pre intervention phase. This may be due to that nurse interns are capable to compensate their important work life and their home life requirements through their different tasks, such as care of elderly, spouse as well as their role as a nurse. Moreover, nurse interns can manipulate their work environment to adjust it with their needs. Nurses have healthy relationships with their managers, colleagues, and other health team members.

Similarly, Abd El-Rasol ${ }^{[29]}$ studies the effect of body mechanics and ergonomics training program on nurses' low back pain and nurses' quality work life, found that the total quality of work life of nurses as well as work life or home life were highly significant variances between the three phases of program evaluation (pre, immediately after and after three months) ( $p=.002, .003)$, respectively.

Concerning the correlation between total knowledge, total ergonomics' practice score and total quality of nursing work life score, the finding of this study discovered that there is highly statistically significant positive correlation between total knowledge regarding workplace ergonomics, total ergonomics' practice score and total quality of nursing work life score throughout intervention phases $(p<.01)$. The previous finding was inconsistent with Bulter et al., ${ }^{[30]}$ who 
explained that the negative intermediate correlations were found between both total body mechanics and ergonomics performs and total quality of nursing work life. Internal consistency was done by Cronbach's Alpha. It was (0.90) for the knowledge questionnaire and (0.94) for the nurse interns' performance observational checklist and (0.92) for Brooks' Quality of Work Life survey.

\section{Strengths and limitations}

The present study has several strengths such as the tools used in this research have been tested for validity and reliability and therefore can be used as they are in related research. The positive correlation between total knowledge, total ergonomics' practice score and total quality of nursing work life score that will help the authors to leave open discussion in a future line of work. However, a number of limitations deserve to be mentioned like some nurse interns did not attend the program sessions as a result of their work commitment in their training area, so some sessions repeated in another day. This limitation can be handled in future researches by grouping nurse interns into small groups to facilitate their attendance. It was so difficult to collect nurse interns from two hospitals in one group to take the program sessions in the booked classroom and this can be handled by giving the program session for nurse interns in each hospital separately. One of the methodological limitations is that the study was carried out in a single university, with a non-randomized sample and without establishing the necessary sample size to ensure generalization of the results.

\section{Conclusions}

This study concluded that workplace ergonomics training intervention had great impact on intern nurses' knowledge, practices, and quality of work life in the immediately post and after three months from training intervention compared to the pre intervention implementation. There are clear dif- ferences between the three phases of the training intervention and total quality of work life. In addition to that, total ergonomics performances were positively connected with quality of nursing work life.

\section{Recommendations}

Pertaining to the findings of the current study, the researchers recommended the following for the future:

(1) Nurse Interns should adhere to safety guidelines in all their practice.

(2) Providing Nurse Interns with safe patient handling and movement training programs.

(3) Maintaining a safety culture to decrease the burden of injuries of work among nurse interns working in different clinical settings.

(4) Distinguishing the Nurse Interns who have positive impact on patients, in terms of care giving by awarding them a prize. This is to improve the quality of work life.

(5) Ensuring the accessibility of ergonomic chairs and automatic adjustable patient beds to manage occupational health hazards.

(6) Conducting periodic training programs for nurse interns to enhance knowledge and performance related to ergonomics principles and decrease the harmful effects of it.

(7) Designing the ergonomics discipline to provide a comprehensive method to occupational safety and nursing interns' satisfaction.

\section{ACKNOWLEDGEMENTS}

The researchers thank the intern nursing students.

\section{CONFlicts OF InTEREST Disclosure}

The authors declare that they have no conflicts of interest.

\section{REFERENCES}

[1] Adelosoye A, Adejumo O, Akinbodewa A, et al. Assessment of Occupational Health Safety and Hazard among Government Health Workers in Ondo City, Southwest Nigeria. British Journal of Medicine \& Medical Research. 2016; 13(8): 1-8. https://doi.org/10.973 4/BJMMR/2016/23620

[2] EH A, EL BANAN HS. Occupational hazards as perceived by nursing interns and protective measures. Journal of Nursing and Health Science. 2016; 5(6): 107-118.

[3] Stumbo DH. Ergonomics programs in Kentucky's nursing homes. Pro Quest Dissertations \& Theses Global. (1896532881). 2017. Available from: https://search.proquest.com/docview/1896532881 ?accountid=178282
[4] International ergonomics association. Definition and Domains of Ergonomics. 2015 [Accessed Dec 5, 2015]. Available from: http: //www.iea

[5] Finch LE, Tomiyama AJ, Ward A. Taking a Stand: The Effects of Standing Desks on Task Performance and Engagement. Int J Environ Res Public Health. 2017; 14(8): 939. PMid: 28825655. https://doi.org/10.3390/ijerph14080939

[6] Thinkhamrop W, Sawaengdee K, Tangcharoensathien V. Burden of musculoskeletal disorders among registered nurses: evidence from the Thai nurse cohort study. BMC Nurs. 2017; 16: 68. PMid: 29200964. https://doi.org/10.1186/s12912-017-0263-x

[7] Yazici ÖS, kalayci I. Evaluation of working environment and conditions of nurses. Süleyman Demirel University, Engineering Sciences 
and Design Magazine. 2015; 3(3): 379-383.

[8] Easton S, Van Laar D, Marlow-Vardy R. Quality of Working Life and the Police.Management. 2013; 3(3): 135-141.

[9] Kelbiso L, Belay A, Woldie M. Determinants of Quality of Work Life among Nurses Working in Hawassa Town Public Health Facilities, South Ethiopia: A Cross-Sectional Study. Nursing Research and Practice. 2017. PMid: 29379654. https ://doi .org/10.1155/20 $17 / 5181676$

[10] Chow M. Assessing the quality of nursing work life in Hong Kong. HNE Handover forNurses and Midwives. 2015; 8(2). Available from: http://journals.sfu.ca/hneh/index.php/hneh/ article/view/375

[11] McCaughey D, McGhan G, Walsh EM, et al. The relationship of positive work environments and workplace injury: Evidence from the National Nursing Assistant Survey. Health Care Management Review. 2014; 39(1): 75-88. PMid: 23416788. https: //doi.org/10.1097/HMR. Ob013e3182860919

[12] Yan P, Yang Y, Zhang L, et al. Correlation analysis between workrelated musculoskeletal disorders and the nursing practice environment, quality of life, and social support in the nursing professionals. Medicine. 2018; 97: 9(e0026). PMid: 29489648. https : //doi.org/10.1097/MD.0000000000010026

[13] National Institute for Occupational Safety and Health (NIOSH). Musculoskeletal health program: Program description. 2012. Available from: https://www.cdc.gov/niosh/programs/msd/descrip tion.html

[14] Ali H, Abdel-Hakeim E. The Effect of Ergonomics Program on Nurses' Knowledge and Practice in Operating Room, IOSR Journal of Nursing and Health Science (IOSR-JNHS). 2018; 7(1): 6-15. Available from: www.iosrjournals.org

[15] Aly A. Occupation hazards facing staff nurses: An intervention study. Thesis submitted in partial fulfillment of the requirement of Doctorate degree in nursing administration, The Military Medical Academy, Cairo. 2014

[16] AORN. Guidelines for safe patient handling in the pre operative setting, pocket references guide. 2007. Available from: http://www.wrha.mb.ca/professionals/safety/fi les/SafePatientHandling/AORNGuidanceStatement.pdf

[17] Brooks BA. Development of an instrument to measure quality of nursing work life. Doctoral dissertation, University of Illinois at Chicago; 2001.

[18] Rasmussen CDN, Hendriksen PR, Svendsen MJ, et al. Improving work for the body - a participatory ergonomic intervention aiming at reducing physical exertion and musculoskeletal pain among childcare workers (the TOY-project): study protocol for a wait-list cluster-randomized controlled trial. Trials. 2018; 19(1): 411. PMid: 30064464. https://doi.org/10.1186/s13063-018-2788-z
[19] Sultan-Taïeb H, Parent-Lamarche A, Gaillard A, et al. Economic evaluations of ergonomic interventions preventing work-related musculoskeletal disorders: a systematic review of organizationallevel interventions. BMC Public Health. 2017; 17(1):935. https : //doi.org/10.1186/s12889-017-4935-y PMid: 29216849.

[20] Radin Umar RZ, Sommerich CM, Lavender SA, et al. Conceptual frameworks for the workplace change adoption process: elements integration from decision making and learning cycle process Ergonomics. 2018; 61(9): 1173-1186. PMid: 29757713. https: //doi.org/10.1080/00140139.2018.1475016

[21] Noor M, Raja MHH, Ghazilla RA. Physical ergonomics awareness in an offshore processing platform among Malaysian oil and gas workers. Int J Occup Saf Ergon. 2018; 1: 1-17.

[22] El Ata G, Khalifa E, El Desouky S, et al. Occupational Risk Factors for Musculoskeletal Disorders among Operation Room Nurses at Cairo University Hospitals, British Journal of Medicine \& Medical Research. 2016; 14(9): 1-11. https://doi.org/10.9734/BJMM $\mathrm{R} / 2016 / 24634$

[23] Afshar M, Bahrami A, Hamedian N. Relationship between knowledge of ergonomics and workplace condition with musculoskeletal disorders among nurses. Researchgate. 2019.

[24] Choi SD, Brings K. Work-related musculoskeletal risks associated with nurses and nursing assistants handling overweight and obese patients: A literature review. Work. 2016; 53(2): 439-448. PMid: 26835850. https://doi.org/10.3233/WOR-152222

[25] Stone DL, Deadrick DL. Challenges and opportunities affecting the future of human resource management. Human Resource Management Review. 2015; 25(2): 139-45. https ://doi.org/10.1016/ j.hrmr.2015.01.003

[26] Tinubu BS, Mbada CE, Oyeyemi AL, et al. Work-Related Musculoskeletal Disorders among Nurses in Ibadan, South-west Nigeria: a cross sectional survey. BMC Musculoskeletal Disorders. 2010; 11: 12-20. PMid: 20089139. https://doi.org/10.1186/1471-247 4-11- 12

[27] Kochitty A. A study to assess the effectiveness of a self-instructional module on the knowledge \& practice regarding proper body mechanics among the critical care nurses in selected hospitals of prune. $\mathbf{J}$ Adv Sci Res. 2015; 6(4): 13-21.

[28] Garg A, Kapellusch JM. Long-term efficacy of an ergonomics program that includes patient-handling devices on reducing musculoskeletal injuries to nursing personnel. Human Factors. 2012; 4 : 608. PMid: 22908684. https://doi.org/10.1177/00187208 12438614

[29] Abd El-Rasol ZM. Effect of Implementing Body Mechanics And Ergonomics Training Program on Nurses Low Back Pain And Quality of Nursing Work Life. IOSR Journal of Nursing and Health Science (IOSR-JNHS). 2017; 7(3).

[30] Bulter V, Clinton C, Sagi H. Applying sciences and strategy to operating room management. Nursing Ergonomics. 2012; 30(5): 275-281. 